SPECIAL COMMUNICATION

\title{
Bhutan: the world's most advanced tobacco control nation?
}

\author{
S Ugen
}

Tobacco Control 2003;12:431-433

\begin{abstract}
Significant achievements in the area of tobacco control have been made in the kingdom of Bhutan in the Eastern Himalayas, following the initiation of several tobacco control activities
\end{abstract}

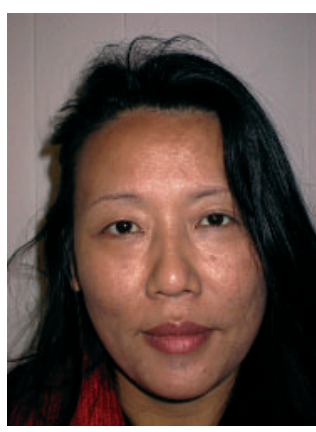

$T$ he kingdom of Bhutan in the Eastern Himalayas remains the world's last surviving Mahayana Buddhist kingdom. Roughly the size of Switzerland, with a population of 698 950, ${ }^{1}$ Bhutan is located between two of the world's most populous countries. Landlocked by the world's highest mountains, it borders the Tibetan region of China in the north and India to the south, west and east. Barely four decades ago, Bhutan had little contact with the rest of the world. However, with changing political and economic circumstances, the kingdom opened its doors to the outside world in the early 1960s. ${ }^{2}$

\section{BUDDHISM AND TOBACCO}

Buddhism is the cornerstone of our development, shaping institutions, arts, drama, architecture, literature, and the social structure including day-to-day lifestyles. Although tobacco is not specifically mentioned in ancient Buddhist texts and the religion is not proscriptive in nature, it has played a pivotal role in maintaining very low smoking rates in the country. The significant influence of religion on the values on the Bhutanese people is also probably responsible for discouraging tobacco farming and manufacture. Cannabis, despite being grown with abundance, is rarely for human consumption.

Bhutan is probably one of the first countries in the world to have had a tobacco control law passed (1729) by the most eminent leader His Holiness Shabdrung Ngawang Namgyal. This has had significant impact on the non-use of tobacco products by monks and the religious community. Religious institutions and important public places like the Dzongs (central administrative offices) have continued to remain tobacco-free and the majority of the older generation abstain from using tobacco products. ${ }^{3}$

\section{CURRENT SITUATION}

Recent times, however, have seen a steady increase in tobacco use, particular among the younger generation. This scenario may be attributed to the increasing pace of modernisation and wider communication, expanding access to electronic and print media. No studies have been conducted to ascertain mortality and morbidity caused by tobacco use, although respiratory infections constitute about $18 \%$ and $25 \%$ of all morbidity in the hospitals and basic health units, respectively. ${ }^{4}$ A recent study found that $8 \%$ chew/ sniff tobacco ( $7 \%$ females and $10 \%$ males.) Smoking prevalence is estimated at $1 \%{ }^{5}$

Recognising the potential implications of tobacco use on the health of the Bhutanese population, the Health Department, with support and guidance from the World Health Organization, initiated a public information campaign on the harmful effects of tobacco use in the mid 1980s. However, the activities undertaken were limited to World No Tobacco Day publicity propagated by the WHO. A turning point in the public health perspective towards tobacco occurred in the early 1990s, when the promotion of healthy lifestyles became an integral part of the health sector plans and policies. Since the institution of the Tobacco and Alcohol Free Initiative Programme in 1998, activities have become more focused and sustained. ${ }^{\circ}$

\section{AT THE PROGRAMME LEVEL}

Tobacco control in Bhutan presents an experience, unique in many aspects from the rest of the world. Religion, culture, and tradition have until now been strong forces against tobacco use. Besides, being small and isolated Bhutan has never been the target of interest for multinational tobacco companies. Hence, major issues concerning tobacco that plague the rest of the world such as the cultivation, manufacture, and direct tobacco advertising is non-existent. While billboards advertising tobacco embellish most of the world, prayer flags adorn the kingdom.

Tobacco control activities have been integrated into the primary health care system since the launch of tobacco control activities in the 1980s. Dissemination of anti-tobacco messages has continued sporadically through religion and health, comprehensive school health, and acute respiratory infection programmes. However, a truly national approach to setting tobacco control priorities within every district has been possible only after the inception of the national tobacco control programme in $1998 .^{6}$ Cost effective measures utilising existing structures in the districts such as the multi-sectoral task forces has made significant contribution in tobacco control.

Advocacy, health education, and dissemination of appropriate information utilising both available media and interpersonal communication are strategies that have been adopted by the tobacco control programme. National activities like the creation of smoke-free places and demand reduction measures such as increases in tobacco import taxes are issues addressed the national level through a multi-sectoral task force. $^{7}$ 


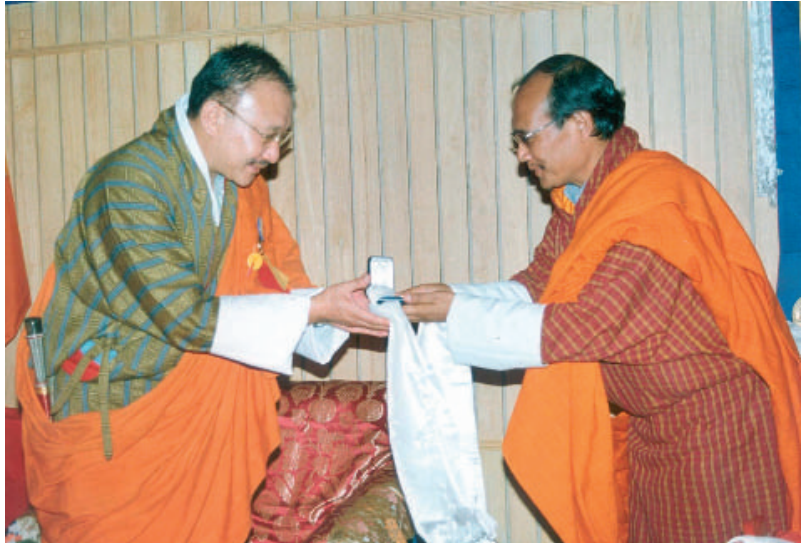

Ministers of Health and Finance at the WHO award for TFI.

However, scarce financial resources, difficult terrain, and scattered communities raise costs of infrastructure and health delivery in Bhutan. Limited access to the modern amenities of communication makes health promotion efforts much more expensive than elsewhere. Competing priorities in health also limit budget allocation and attention to the tobacco program. Moreover, a dearth of in-depth formative research and baseline surveys for tobacco control impede policy recommendations.

Despite the constraints, significant achievements in the area of tobacco control have been made in Bhutan since the initiation of tobacco control activities. Currently, 19 out of 20 Districts have banned the sale of tobacco. Most work places, holy premises, educational institutions, health centres, public gatherings, and public transportation throughout the nation have been declared tobacco-free. To date the nation has been awarded eight medals for initiatives undertaken for tobacco control. ${ }^{7}$ The leadership, guidance, and support from the highest level compounded by the commitment at individual, community, district, and national level have been exemplary and the key to achievements in the tobacco control area.

\section{THE SUCCESS STORY}

\section{Strong political commitment}

Under the dynamic leadership of His Majesty King Jigme Singye Wangchuck, the nation has experienced tremendous progress in all areas of the developmental process. Promotion of healthy lifestyles is an important element of our developmental goals, the well being of the individual, the family, the community, and the nation is high on the royal government's

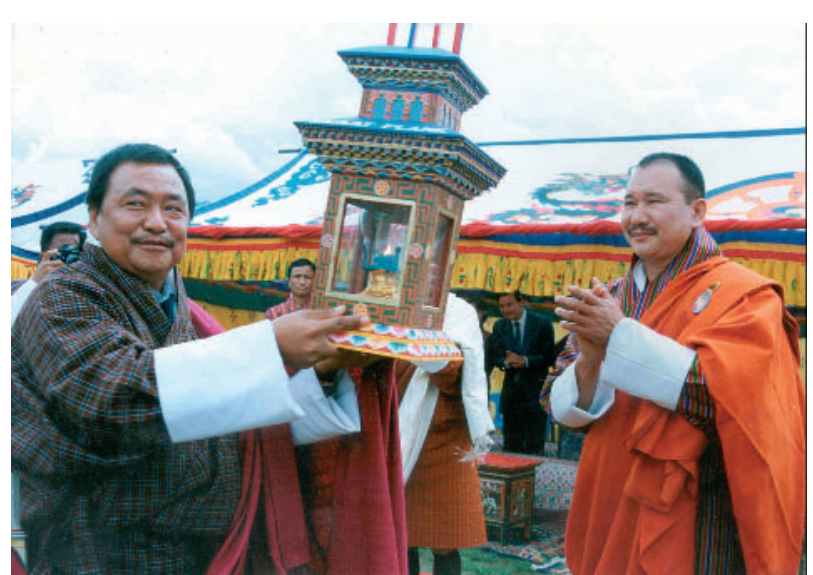

SEAT flame ceremony in Thimphu. agenda. An average allocation of $11 \%$ of the government expenditures for health reflects this high commitment to the health sector. ${ }^{8}$

Over the years Her Majesty the Queen, Ashi Sangay Choden Wangchuck, has been actively involved in promoting social causes, especially in the field of health. Royal visits have been scheduled to remote Bhutanese hamlets, numerous schools, and health centres that dot the valleys of Bhutan. Besides advocating important health issues, which include tobacco control, drug abuse and reproductive health, Her Majesty has personally chaired discussions in districts involving multi-sectoral task forces, students, and the general public.

Under the vibrant leadership and guidance of the Minister of Health and Education these campaigns paved the way for a coordinated and multi-sectoral initiative for tobacco control activities in the country. His Excellency's initiatives in the area of tobacco control have already been recognised by WHO.

\section{National and district committees}

Districts have generated tremendous support for activities and campaigns associated with tobacco control through multi-sectoral task forces. Since their establishment in the year 2000 all districts have passed regulations and monitored activities concerning tobacco control. Several districts have also issued notifications in the media informing visiting travellers to abstain from using tobacco in their areas.

A high powered national multi-sectoral task force for tobacco control, comprising key decision makers of individual ministries and organisations, addresses future concerns of the Bhutan tobacco-free programme. The recent ban on the sales of duty-free tobacco products has resulted from this collaboration. ${ }^{10}$

Active support and participation of the religious body Success in the area of tobacco control, can to a large extent, be attributed to support from the highest ecclesiastical level and direct monastic campaigns against tobacco through the religion and health programme. In Bhutan monks are held in high esteem and are considered central to the community. Intimately involved in the lives of people, they provide advice and guidance on matters related to birth and death, prayer and celebration. Therefore their involvement in tobacco control is seen as critical.

The head of the ecclesiastic body in Bhutan, His Holiness the Je Khenpo, has made numerous public statements on the ill effects of tobacco and endorsed the booklet "Buddhist perspectives on tobacco" ${ }^{\prime 11}$ The response to such an initiative

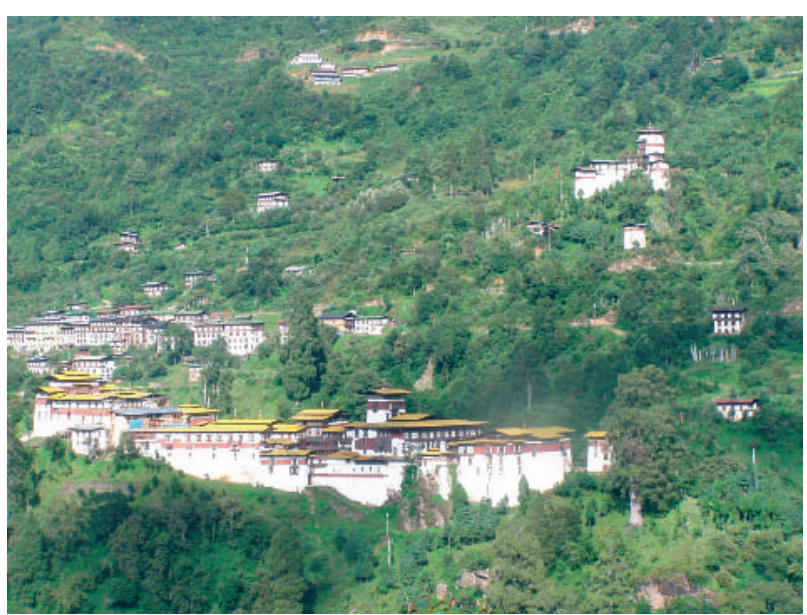

Trongsa Dzong 
is very encouraging and central monastic body has also received recognition by WHO for their efforts in tobacco control.

\section{Challenges}

Despite current successes in issues related to the harmful effects of tobacco there are still substantive challenges. Scarce programme resources, a paucity of national data, and sustaining the active involvement of other sectors are some of the hurdles. Predicted increases in smoking trends among youth who comprise $43 \%$ of the nation's population implies that legislative and price measures for tobacco control be given high priority. The absence of such measures could possibly dilute past achievements. However, given the multitude of positive social, cultural, political, and environmental factors, compounded by the extraordinary leadership and commitment at all levels, the prospects of creating a tobacco-free nation remain bright.

\section{REFERENCES}

1 Central Statistical Organization. Statistical Yearbook of Bhutan 2001. Royal Government of Bhutan Thimphu. Catalogue No. 101, November 2001.

2 Bhutan 2020. A vision for peace, prosperity and happiness. Planning Commission. Royal Government of Bhutan, 1999.

3 Tobacco or Health. Country profile Bhutan, 2000. Tobacco and Alcohol Free Initiative program, IECH Division Ministry of Health and Education (unpublished).

4 Annual Health Bulletin 2000. Planning and Policy division. Ministry of Health and Education, Bhutan.

5 KAP Survey 2000, Information, Education and Communication for Health Division. Department of Health, Ministry of Health and Education, Bhutan.

6 Tobacco and Alcohol Free Initiative program report 2000 (unpublished).

7 Programme report 2001. Tobacco and Alcohol Initiative programme (unpublished).

8 Planning and Policy Division, Ministry of Health and Education, 1999.

9 Program report 2002. Tobacco and Alcohol Free Initiative programme (unpublished).

10 Programme report 2003. Tobacco and Alcohol Free Initiative programme (unpublished).

11 Programme report 1999. Tobacco and Alcohol Free programme (unpublished).

\section{The lighter side}

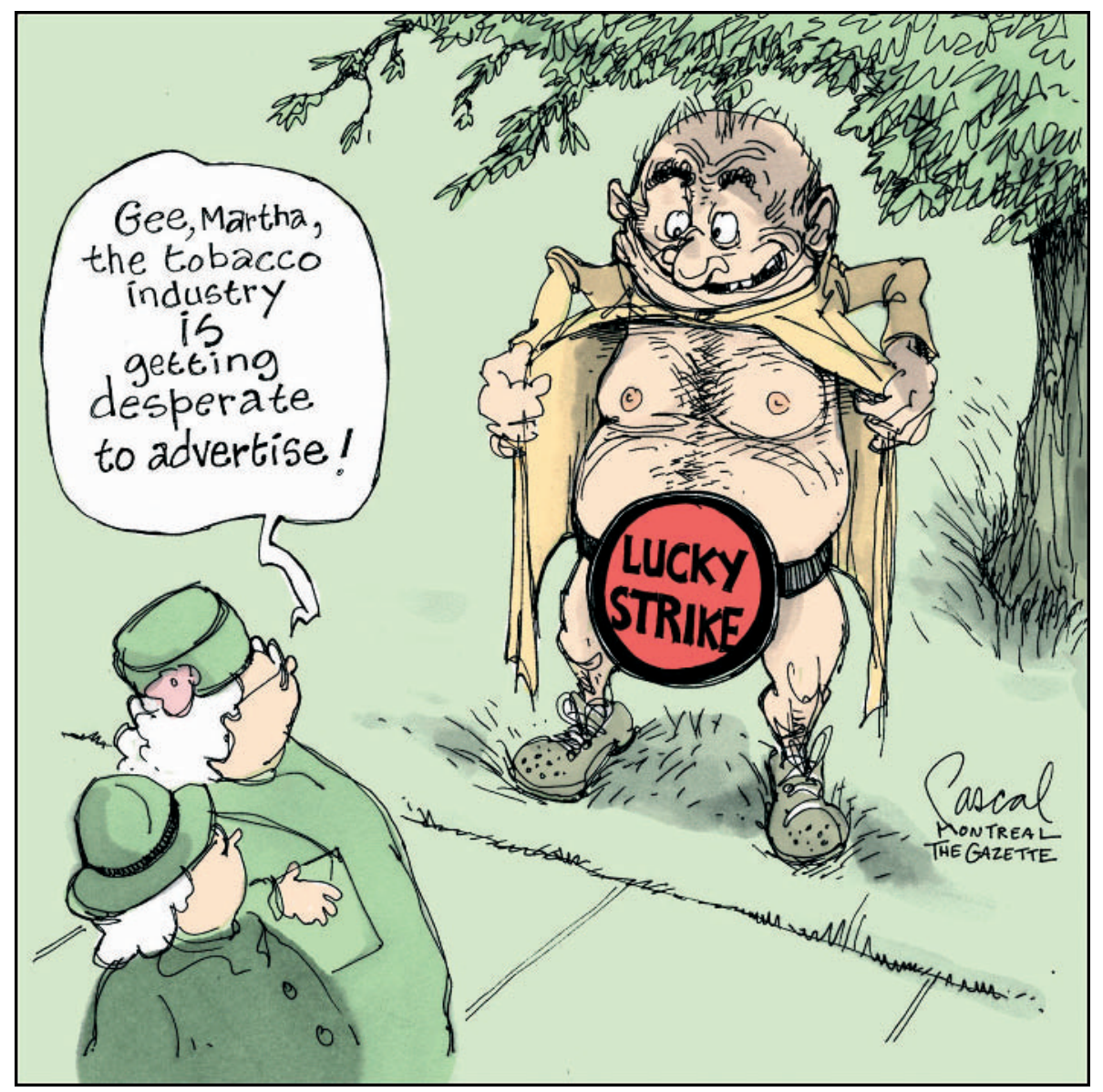

(c) Pascal, The (Montreal) Gazette. 